\title{
EVALUASI PENERAPAN SISTEM INFORMASI MANAJEMEN PUSKESMAS (SIMPUS) DENGAN METODE HOT-FIT DI PUSKESMAS GATAK
}

\author{
Anggita Pramesti Putri Cahyani ${ }^{*}$, Fahmi Hakam², Fiqi Nurbaya ${ }^{3}$ \\ 1Prodi Rekam Medis dan Informasi Kesehatan, Fakultas Kesehatan Masyarakat \\ Universitas Veteran Bangun Nusantara \\ *email :prayulia123@gmail.com
}

\begin{abstract}
Information system evaluation is the process of knowing the extent of the information system. From a preliminary study of researchers in the health center gatak about the number of human resources has been found that the lack of human resources is competent in the it field, not all officers understand the use of the Health Center Management Information System (HCMIS), sometimes an error server causes a breakdown in service processes. The purpose of this study is to evaluate the application of Health Center Management Information System in the health center gatak and know the use of quality services indicator Health Center Management Information System by explaining the compatible systems component that is human, technology and organization. This type of research is a descriptive analytic study with a qualitative approach. Research subject exist six is the head of medical records, one operator polyclinic, Hcmis coordinator, one Hcmis operator, head of the medical center, and one pharmacist. The sample retrieval technique used is purposive sampling. The results of this study, is known to what extent the Health Center Management Information System program is running, to provide input for an evaluation at health center gatak for the front because human, technology, and organization compatibility really does affect information systems. It is hoped that there will be periodic training so that the implementation of Health Center Management Information System use becomes easier.
\end{abstract}

Keywords: Evaluation, Health Center Management Information System, HOT-Fit Method.

\begin{abstract}
ABSTRAK
Evaluasi sistem informasi adalah proses mengetahui sejauh mana suatu sistem informasi berjalan. Dari studi pendahuluan yang telah dilakukan peneliti di Puskesmas Gatak tentang jumlah SDM di Puskesmas Gatak ditemukan bahwa kurangnya SDM yang berkompeten dalam bidang IT, belum semua petugas memahami penggunaan SIMPUS, terkadang server eror sehingga menyebabkan proses pelayanan menjadi terganggu. Tujuan penelitian ini adalah untuk mengevaluasi penerapan SIMPUS di Puskesmas Gatak dan mengetahui indikator pelayanan mutu terkait penggunaan SIMPUS dengan menjelaskan kesesuaian antara komponen sistem yaitu manusia, organisasi dan teknologi. Jenis Penelitian ini adalah penelitian analitik deskriptif dengan pendekatan kualitatif. Subjek penelitian ada 6 yaitu kepala Rekam Medis, 1 petugas Poli Lansia, 1 Koordinator SIMPUS, 1 petugas Operator SIMPUS, Kepala puskesmas, dan 1 petugas Farmasi. Tehnik pengambilan sampel yang digunakan adalah purposive sampling. Hasil penelitian ini, diketahui sejauh mana program SIMPUS berjalan, memberikan masukan untuk dijadikan evaluasi bagi Puskesmas Gatak untuk kedepannya karena kesesuaian antara manusia, teknologi, dan organisasi sangat berpengaruh untuk sistem informasi.Diharapkan ada pelatihan berkala terkait SIMPUS sehingga implementasi penggunaan SIMPUS menjadi lebih mudah.
\end{abstract}

Kata Kunci: Evaluasi, Sistem Informasi Manajemen Puskesmas, Model HOT-Fit. 


\section{PENDAHULUAN}

Sistem Informasi Puskesmas ialah suatu tatanan yang menyediakan informasi untuk membantu proses pengambilan keputusan dalam melaksanakan manajemen puskesmas untuk mencapai sasaran kegiatannya. Pencatatan adalah serangkaian kegiatan untuk mendokumentasikan hasil pengamatan, pengukuran atau perhitungan pada setiap langkah upaya kesehatan yang dilaksanakan Puskesmas (Permenkes RI, No. 31 Tahun 2019). Pusat Kesehatan Masyarakat atau Puskesmas merupakan fasilitas

pelayanan kesehatan yang menyelenggarakan upaya kesehatan masyarakat, dan upaya kesehatan perseorangan tingkat pertama, dengan lebih mengutamakan upaya promtif dan preventif di wilayah kerjanya (Permenkes RI, No. 43 Tahun 2019).Sistem Informasi Manajemen Puskesmas (SIMPUS) ialah aplikasi yang membantu kegiatan pencatatan dan pelaporan di Puskesmas. Sejatinya SIMPUS merupakan pengembangan dari SP2TP yang merupakan kegiatan pencatatan dan pelaporan secara manual. Keberadaan SIMPUS terkomputerisasi, akan sangat membantu petugas dalam menyajikan informasi secara cepat, tepat dan dapat dipercaya, sehingga informasi yang disajikan puskesmas dapat dipakai untuk pengambilan keputusan di berbagai tingkat sistem kesehatan dan berbagai jenis manajemen kesehatan, sehingga dapat meningkatkan mutu pelayanan kepada masyarakat (Hakam, 2016).Evaluasi sistem informasi yaitu suatu proses untuk menggali dan mencari tahu, tentang sejauh mana suatu kegiatan implementasi sistem informasi, baik dari sudut pandang persepsi, pengguna, organisasi, maupun dari segi sistem teknologi sistem informasinya (Hakam, 2016). Menurut Sari dalam Safitri (2017) standar yang dipakai untuk mengevaluasi suatu kegiatan tertentu dapat dilihat dari tiga aspek utama yaitu :

1. Utility (manfaat)

Hasil evaluasi hendaknya bermanfaat bagi manajemen untuk

pengambilan keputusan atas program yang sedang berjalan.

2. Accuracy (akurat)

Informasi atas hasil evaluasi

hendaklah memiliki tingkat ketepatan tinggi.

3. Feasibility (layak)
Hendaknya proses evaluasi yang dirancang dapat dilaksanakan secara layak.

Menurut Hakam (2016) metode ini mencoba mengevaluasi penggunaan sistem informasi, dengan menempatkan kompenen penting dalam informasi yakni Human (Manusia) - Organization (Organisasi) Technology (Teknologi) serta kesesuaian diantara ketiga komponen tersebut. Kriteria yang dapat digunakan untuk menilai kualitas informasi antara lain adalah kelengkapan, keakuratan, ketepatan waktu, ketersediaan, relevansi, konsistensi dan data entry. Sedangkan kualitas layanan berfokus pada keseluruhan dukungan yang diterima oleh service provider sistem atau teknologi. Service quality dapat menilai dengan kecepatan respon, jaminan, empati dan tindak lanjut layanan.Menurut Evrilyan (2017) HOT FIT adalah salah satu kerangka teori yang dipakai untuk mengevaluasi system informasi. Model ini adalah kombinasi dari Model Kesuksesan sistem informasi dari Delonedan Mclean dan IT Organization Fit Model dari Morton. Model HOT-FIT menjelaskan secara komprehensif berupa interpretasi komleksitas, hubungan timbal balik antara orang, organisasi, proses, dan teknologi. Metode evaluasi ini memperjelas semua komponen yang terdapat dalam sistem informasi itu sendiri. Berdasarkan hasil studi pendahuluan yang telah dilakukan peneliti tentang jumlah SDM di Puskesmas Gatak ditemukan bahwa kurangnya SDM yang berkompeten dalam bidang IT, belum semua petugas memahami penggunaan SIMPUS sehingga perlu diadakan pelatihan berkala agar implementasi pengggunaan.

\section{METODE PENELITIAN}

Jenis Penelitian ini adalah penelitian analitik deskriptif dengan pendekatan kualitatif dengan tujuan untuk mendapatkan suatu gambaran atau deskripsi suatu keadaan sebenarnya. Penelitian ini dilaksanakan di Puskesmas Gatak Kabupaten Sukoharjo, waktu penelitian yang dilaksanakan peneliti yaitu bulan Maret sampai Juni 2020.

Pengambilan sampel dalam penelitian ini dilakukan secara purposivesampling. 
Purposive sampling adalah pengambilan sampel yang didasarkan pada suatu pertimbangan tertentu yang dibuat oleh peneliti sendiri, berdasarkan ciri atau sifat yang sudah diketahui sebelumnya yaitu 6 orang yang terdiri dari 1 Kepala Rekam Medis, 1 Petugas Poli Lansia,1 Koordinator SIMPUS, 1 Petugas Operator SIMPUS, Kepala Puskesmas, dan 1 Petugas Farmasi. Teknik pengumpulan data yang dilakukan yaitu dengan wawancaradimana peneliti mendapatkan keterangan atau informasi secara lisan dari sasaran seseorang penelitian.

\section{SIMPUS menjadilebih mudah,}

terkadang server eror sehingga menyebabkan proses pelayanan menjadi terganggu dan belum ada SOP pengoperasian SIMPUS di setiap poli sehingga perlu pengadaan SOP agar langkah-langkah pengentrian data sesuai standar yang telah ditetapkan. Berdasarkan permasalahan diatas maka perlu dilakukan evaluasi penerapan SIMPUS di Puskesmas Gatak, untuk mengetahui indikator pelayanan mutu terkait penggunaan SIMPUS dengan menjelaskan kesesuaian antara komponen sistem yaitu manusia, organisasi dan teknologi. Tujuan dari penelitian ini, mengevaluasi SDM, Aspek Hukum Organisasi, dan Teknologi yang berkaitan dengan Sistem Informasi Manajemen Puskesmas. (responden) atau dengan bercakap-cakap secara langsung dengan responden tersebut, jadi data yang diperoleh langsung dari responden melalui suatu percakapan. Peneliti melakukan wawancara kepada Kepala Rekam Medis, petugas poli lansia, operator SIMPUS, koordinator SIMPUS, Petugas farmasi dan Kepala Puskesmas Gatak untuk mengetahui secara langsung tentang penggunaan SIMPUS. Observasi dimana peneliti melihat, mendengar dan mencatat sejumlah dan taraf aktivitas tertentu atau situasi tertentu yang ada hubungannya dengan masalah yang diteliti, studi dokumentasi serta triangulasi sumber, hasil dari observasi yang dilakukan oleh peneliti untuk human (manusia) kegiatan dan entri data layanan di setiap poli sudah sesuai dengan standar prosedur, organization (organisasi) yaitu menggunakan telusur dokumen yang telah ada, dan technology (teknologi) yaitu informasi tentang komputer. Studi Dokumentasi ialah cara pengumpulan data dengan dokumentasi menggunakan dokumen-dokumen yang telah ada.
Penelitian ini menggunakan check list untuk mengetahui evaluasi di bagian organisasi tentang kebijakan dan standar operasional prosedur dan triangulasi sumber menurut Mamik (2015) ialah menggali kebenaran informasi tertentu melalui berbagai metode dan sumber perolehan data. Misalnya selain wawancara dan observasi peneliti bisa menggunakan observasi terlibat (participant observation), dokumen tertulis, arsif, dokumen sejarah, catatan resmi, tulisan pribadi, gambar atau foto. Hasil analisis data disajikan ke dalam bentuk tabel dan narasi dengan menggambarkan secara lengkap sehingga dapat diketahui hasil evaluasi SIMPUS.Penelitian ini menggunakan analisis data, yaitu kualitatif deskriptif dengan menggambarkan secara lengkap dan tepat data yang diperoleh dari wawancara, observasi, dan studi dokumentasi kemudian dapat diketahui hasil evaluasi penerapan SIMPUS sesuai dengan metode hotfit.

\section{HASIL}

\section{Persepsi Penggunaan Terhadap Sistem Informasi}

Dari hasil wawancara tentang ada tidaknya pelatihan yang pernah diikuti dapat disimpulkan bahwa sudah dilakukan awal penerapan SIMPUS oleh Dinas Kesehatan pada saat SIMPUS launching tahun 2007 dan dilakukan juga In House Training atau pelatihan internal di puskesmas yang diikuti oleh petugas operator SIMPUS yang belum pernah terpapar pelatihan sehingga agar petugas bisa menggunakan SIMPUS, namun belum ada SDM yang berkompeten dalam bidang IT dan perlu ada nya pelatihan berkala terkait SIMPUS agar implementasi penggunaan SIMPUS agar implementasi SIMPUS menjadi lebih mudah 
Tabel 1 Aspek Human

\begin{tabular}{|c|c|c|c|}
\hline \multirow[t]{2}{*}{ Objek } & \multirow[t]{2}{*}{ Observasi } & $\begin{array}{c}\text { Kesesuaian } \\
\text { dengan SOP }\end{array}$ & \multirow[t]{2}{*}{ Keterangan } \\
\hline & & Tidak & \\
\hline \multirow{5}{*}{ Human } & $\begin{array}{ll}\text { Kegiatan } & \text { pelayanan } \\
\text { pendaftaran } & \end{array}$ & $\mathrm{v}$ & $\mathrm{SPO} / \mathrm{PDF} / 12 / \mathrm{I} / 2017$ \\
\hline & Entry data layanan poli anak & $\mathrm{v}$ & SPO/II/0105/ADM/IV/2017 \\
\hline & Entry data layanan poli gigi & $\mathrm{V}$ & SPO/II/0105/ADM/IV/2017 \\
\hline & Entry data layanan poli Lansia & $\mathrm{v}$ & SPO/II/0105/ADM/IV/2017 \\
\hline & Entry data layanan poli Umum & $\mathrm{v}$ & SPO/II/0105/ADM/IV/2017 \\
\hline
\end{tabular}

Tabel 1 di atas menerangkan aspek human bahwa entri data sudah sesuai dengan Standar Operasional Prosedur yang ada, namun sebaiknya diadakan SOP di setiap poli, langkah- langkah dalam menggunakan SIMPUS untuk memasukkan data agarsesuai dengan standar operasional yang telah ditetapkan dan data yang dilaporkan ke Dinas Kesehatan akurat.

\section{Dukungan dan Kebijakan Organisasi}

Dari hasil wawancara tentang dukungan dan kebijakan organisasi dapat disimpulkan bahwa dukungan dari organisasi sudah baik, dukungan dari semua aspek berupa sarana kebutuhan komputer dan kelengkapan nya ada dalam perencanaan, pencatatan dan pelaporan dilakukan secara online.

Tabel 2 Aspek Organization

\begin{tabular}{ccccc}
\hline No & Organization & Ada & $\begin{array}{c}\text { Tidak } \\
\text { Ada }\end{array}$ & Keterangan \\
\hline 1 & Kebijakan tertulis terkait & $\mathrm{v}$ & & Permenkes RI Nomor 31 Tahun 2019 \\
& SIMPUS & & $\mathrm{v}$ & SK 440/5768/X/2019 \\
2 & SK penetapan petugas & $\mathrm{v}$ & SPO/II/0105/ADM/IV2017 \\
3 & SOP penggunaan SIMPUS & $\mathrm{v}$ & SK 440/5768/X/2019 \\
4 & Penanggungjawab SIK & $\mathrm{v}$ & 1 (satu) bulan sekali \\
5 & Proses Monitoring & $\mathrm{V}$ & \\
\hline
\end{tabular}

\section{Kualitas Sistem Informasi}

Dari hasil wawancara yang dilakukan peneliti tentang kualitas sistem informasi dapat disimpulkan bahwa untuk kelengkapan informasinya baik, keakuratan informasi yang dihasilkan dapat di katakan akurat jika dimasukkan rutin setiap hari dan diisi lengkap oleh kepala puskesmas untuk menggunakan SIMPUS selain itu juga dilakukan monitoring berkala setiap 1 (satu) bulan.

Tabel 3 Aspek Technology

\begin{tabular}{ccc}
\hline Objek & Observasi & Keterangan \\
\hline & Tampilan SIMPUS & Friendly, simple. \\
Menu SIMPUS & Mudah dipelajari, lengkap, tidak rumit. \\
Monitor Pemeliharaan & Dilakukan setiap hari selama satu \\
& & bulan. \\
Technology & Jumlah Komputer yang dipakai & 11 unit. \\
RAM & $4 \mathrm{~GB}$. \\
Intel Pentium & Core i3. \\
& Sistem Operasi yang digunakan & Windows 10. \\
Bahasa Pemrograman yang & Voxpro. \\
digunakan & Lifi & Loading lama. \\
\hline
\end{tabular}


Tabel 3 di atas menerangkan mengenai aspek technology (teknologi) bahwa tampilan dan menu SIMPUS friendly, simple, lengkap dan tidak rumit. Komputer yang digunakan berjumlah 11 spesifikasi yang cukup baik dengan sistem operasi windows 10 dan selalu ada monitor pemeliharaan yang dilakukan setiap hari selama satu bulan, hanya saja untuk kecepatan wifi yang digunakan terkadang loading lama.

\section{PEMBAHASAN \\ Persepsi Penggunaan terhadap Sistem Informasi}

Menurut Hakam (2016) pendidikan dan pelatihan mencakup perencanaan kebutuhan Pendidikan yang akan diikuti oleh pegawai yang berkaitan dengan tugas \& tanggungjawab serta realisasi Pendidikan yang berupa pencatatan data Pendidikan dan pelatihan yang pernah diikuti. Untuk memastikan kekuatan dan kesiapan SDM dalam pengembangan system informasi manajemen disebuah organisasi, maka manajemen harus lebih dahulu mengukur kekuatan SDM SI/IT dan knowledge dari pengguna system. Hal ini sesuai dengan teori Yapary (2013) bahwa setiap SDM pada sebuah perusahaan atau organisasi pastinya sangat menginginkan pengembangan karier. Pengembangan karir diperuntukkan bagi mereka yang layak menerimanya yaitu bagi SDM yang berkompeten. Hal ini didukung oleh teori Andrew E dalam Felisita (2016) bahwa pelatihan pada sebuah organisasi ditujukan kepada karyawan pelaksana dalam rangka meningkatkan pengetahuan dan keterampilan teknis. Sedangkan menurut Handoko dalam Felisita (2016), pelatihan dimaksudkan untuk memperbaiki penguasaan berbagai keterampilan dan pelaksanaan tehnik pekerjaan tertentu terperinci dan rutin.

\section{Dukungan dan Kebijakan Organisasi}

Menurut Hakam (2016) dukungan

dan kebijakan organisasi sangat menentukan pengembangan sistem informasi, dapat juga dikatakan bahwa sukses atau tidaknya penerapan informasi, tergantung dari kebijakan dan dukungan yang diberikan dari pimpinan atau manajemen dalam sebuah organisasi. Sedangkan Menurut Jogiyanto dalam Ikhsan dan Bustamam (2016) berpendapat bahwa salah satu bentuk dukungan manajemen adalah menyediakan fasilitas berupa pelatihan dan memberikan bantuan kepada pemakai sistem ketika menghadapi permasalahan-permasalahan yang terkait.

\section{Kualitas Sistem Informasi}

Menurut Hakam (2016) dalam pengembangan SI, manajemen atau pengelola organisasi juga harus jeli dalam melihat kondisi dan ketersediaan infrastruktur yang ada, karena meskipun memiliki aplikasi yang bagus, namun tidak ditunjang dengan infrastruktur atau teknologi yang memadai, maka SIM tidak akan dapat beroperasi secara maksimal. Hal ini sesuai dengan teori James dalam Ikhsan dan Bustamam (2016) bahwa suatu sistem dinilai berjalan secara efektif apabila mampu memenuhi kebutuhan dan keinginan informasi yang berkualitas kepada pengguna yang ada dalam perusahaan baik secara individual maupun secara kelompok. Informasi tersebut berkualitas apabila akurat, tepat waktu, lengkap dan ringkas.

\section{SIMPULAN}

1. Pelatihan SIMPUS sudah dilaksanakan dari Dinas Kesehatan maupun di Puskesmas Gatak yaitu dengan in house training, pelatihan dilakukan kepada semua petugas yang menggunakan SIMPUS, namun belum semua petugas memahami penggunaan SIMPUS.

2. Standar Operasinal Prosedur SIMPUS sudah ada namun belum ada SOP disetiap poli untuk entri data, sehingga langkah-langkah pengoperasian SIMPUS untuk entri data masih jadi satu dengan SOP SIMPUS. Dengan adanya fasilitas yang membantu pemakai sistem, akan meningkatkan kemampuan dan memudahkan pemakai sistem untuk menghasilkan informasi yang berkualitas. Kualitas sistem informasi yang dihasilkan oleh SIMPUS selalu akurat apabila semua data diisi dengan tepat, namun kenyataan nya tidak akurat karena data nya tidak valid, tidak diselesaikan di hari yang sama terkadang data dimasukkan oleh petugas lain.

3. Puskesmas Gatak untuk koneksi wifi yang digunakan terkadang loading lama, sehingga memperlambat pelayanan. Maka dari itu 
kecepatan wifi perlu disesuaikan dengan Erawantini, F., Kurnia, W., \& Tevalys, P. penggunaan.

\section{UCAPAN TERIMA KASIH}

Sepanjang proses dalam penyusunan KTI ini, penulis mendapat dukungan, bantuan serta do'a dari berbagai pihak, oleh karena itu dalam kesempatan ini penulis menyampaikan rasa terimakasih yang tiada terhingga kepada yang terhormat :

1. Ibu Titik Haryanti, S.KM., M.P.H selaku Dekan Fakultas Kesehatan Masyarakat Universitas Veteran Bangun Nusantara Sukoharjo.

2. Bapak Fahmi Hakam, S.KM., M.P.H selaku Ketua Program Studi D3 Rekam Medis dan Informasi Kesehatan serta sebagai pembimbing yang telah memberikan bimbingan dan arahan kepada penulis dalam menyelesaikan KTI.

3. Ibu Fiqi Nurbaya, S.KM., MKes selaku pembimbing yang telah memberikan bimbingan dan arahan kepada penulis dalam menyelesaikan KTI.

4. Bapak drg. Tri Prasetyo Nugroho, MM selaku Kepala Puskesmas Gatak yang telah memberikan kesempatan dalam melaksanakan penelitian.

5. Ibu Eka Setiawaty, A.Md. PK selaku Kepala Rekam Medis Puskesmas Gatak yang telah membimbing dan memberikan arahan kepada peneliti dalam menyelesaikan KTI.

6. Seluruh petugas Puskesmas Gatak, yang telah bersedia membimbing, berbagi pengalaman dan membantu untuk memperoleh data, terutama bagian sistem informasi puskesmas.

\section{DAFTAR PUSTAKA}

Aprilia, $\quad$ D. 2018. Evaluasi Sistem Informasi Manjemen Rumah Sakit dengan Menguunakan Model Human Organization and Technology Fit. Thesis.

Diantono, P., Wahyu, W., \& Henderi. 2018. Evaluasi Penerapan SIMRS Mengunakan Metode Hot-Fit di RSUD Dr. Soedirman Kebumen.Vol : 2 Hal : 46.
2016. Sistem Informasi Manajemen

Puskesmas (SIMPUS) Kencong

Kabupaten Jember dengan Metode End User Computing (EUC) Satisfaction Kesehatan, Vol : 4 Hal: 1-13.

Fanny, N., Adi, K., Patria J. 2019. Penerapan Model Hot Fit pada Evaluasi Sistem Informasi Keselamatan dan Kesehatan Kerja di RSUD Dr. Moerwadi.

Felisita. 2016. Pengaruh Pelatihan, Pengembangan, Kompensasi dan Motivasi Terhadap Kinerja Karyawan. Yogyakarta.

Hakam,Fahmi. 2016. Analisis, Perancangan dan Evaluasi Sistem Informasi Kesehatan. Yogyakarta: Gosyen Publishing.

Haryanto, A. 2014. Evaluasi Implementasi Sistem Informasi Manajemen Puskesmas di Kabupaten Bantul.

Ikhsan, M., dan Bustamam. 2016. Pengaruh Dukungan Manajemen Puncak dan Kemampuan Teknik Operator Sistem Informasi Akuntansi Terhadap Kualitas Informasi Akuntansi.Vol: 1 Hal: 36-46.

Krisbiantoro, D., Suyanto., Taufiq. 2015. Evaluasi Keberhasilan Implementasi Sistem Informasi dengan Pendekatan Hot-Fit Model Perpustakaan STMIK AMIKOM Purwokerto.

Kementerian Kesehatan RI. 2004. Keputusan Menteri Kesehatan Nomor 128/Menkes/SK/II/2004Tenta ng Kebijakan Dasar Pusat Kesehatan Masyarakat. Jakarta.

Kementerian Kesehatan RI. 2019. Keputusan Menteri Kesehatan Nomor 43 Tahun 2019 tentang Pusat Kesehatan Masyarakat. Jakarta.

Kementerian Kesehatan RI. 2014. Peraturan Menteri Kesehatan Republik Indonesia Nomor 75 Tahun 2014 tentang Pusat Kesehatan Masyarakat. Jakarta.

Kementerian Kesehatan RI. 2019. Peraturan Menteri Kesehatan Republik Indonesia Nomor 31 Tahun 2019 tentang Sistem Informasi Puskesmas. Jakarta.

Kementerian Kesehatan RI. 2014. Peraturan Menteri Kesehatan Republik Indonesia 
Nomor 46 Tahun 2014 tentang Sistem Informasi Kesehatan. Jakarta.

Laelatul, F. 2019. Evaluasi Penerapan Sistem Informasi Manjemen Puskesmas (SIMPUS) melalui Metode Pieces Layanan Kunjungan Rawat Jalan Puskesmas Bogor Utara.

Mamik. 2015. METODOLOGI

KUALITATIF. Edited by M. C.

Anwar. Sidoharjo: Zifatama.

Mulyadi, D., Choliq Abdul. 2017. Penerapan Metode Human Organization Technology (HOT-Fit Model) untuk Evaluasi Implementasi Aplikasi Sistem Informasi Persediaan (SIDIA) di Lingkungan Pemerintah Kota Bogor. Hal : 1-12.

Patimila, H. 2013. Metode Penelitian Kualitatif. Jakarta: Alfabeta.

Prasetyowati, A., Kushartanti, R. 2018. User Satification Analysis of Primary Care Information Systems in Semarang City with EUCS Model.

Purwanto, E. 2014. Evaluasi Penerapan Sistem Informasi Akademik Terintegrasi pada STMIK Duta Bangsa Surakarta. ISSN:2086-9436, Vol: 6 Hal 11-18.

Rina, A., Tri S., Supatman. 2018. Evaluasi Sistem Informasi Manajemen Rumah Sakit (SIMRS) pada Bagian Pendaftaran Rawat Jalan dengan Metode HOT-FIT.

Rusdiana, A., Irfan M. 2014. Sistem Informasi Manajemen. Bandung: Pustaka Setia.

S, Notoadmodjo. 2014. Metodologi Penelitian Kesehatan. Jakarta: Rineka Cipta

Safitri, D. 2017. Evaluasi Penerapan Sistem Informasi Pelayanan Dengan Menggunakan Metode Hot-Fit (Studi kasus: PT Taspen (Persero) KC Pekanbaru).

Septiana, A. 2017. Pengertian

Teknik Analisis. Jakarta: Edi publisher.

Thenu, V. J., Sediyono, E., \& Purnami, C. T. 2016. Evaluasi Sistem Informasi Manajemen Puskesmas Guna Mendukung Penerapan SikdaGenerik Menggunakan Metode Hot Fit Di Kabupaten Purworejo. Jurnal Manajemen Kesehatan Indonesia, 4(2), 129-138.

Wahyuni, V., Maita,I. 2015. EVALUASI SISTEM INFORMASI MANAJEMEN

\section{RUMAH SAKIT (SIMRS) \\ MENGGUNAKAN METODE UNIFIED \\ THEORY OF ACCEPTANCE AND USE OF TECHNOLOGY (UTAUT).}

Yapary FV. 2013. Pengaruh Sistem

Informasi Manajemen SDM Terhadap

Pengambilan Keputusan Pengembangan

Karir PadaPt. Bank Tabungan Pensiun

Nasional,Tbk, Cabang

Manado.https://ejournal.unsr

at.ac.id/index.php/jia/article/

viewFile/6246/578(Diakses 25 Juni 2020 
Jurnal Manajemen Informasi dan Administrasi Kesehatan (JMIAK)

ISSN: 2621-6612 | Email:jmiakmedrec@gmail.com

Volume 03 Nomor 02 November 2020 Halaman 20-26 